08

\title{
Наноструктурная самоорганизация и динамическая адаптация металлополимерных трибосистем
}

\author{
(C) Ю.К. Машков
}

Омский государственный технический университет, 644050 Омск, Россия

e-mail: malij_olga@mail.ru

(Поступило в Редакцию 28 июня 2016 г.)

\begin{abstract}
Проанализированы результаты исследования влияния наноразмерных модификаторов полимерной матрицы на процессы наноструктурной самоорганизации полимерных композитов и динамической адаптации металлополимерных трибосистем, оказывающих существенное влияние на износостойкость полимерных композиционных материалов. Показано, что в металлополимерных трибосистемах развиваются физико-химические процессы наноструктурной самоорганизации с образованием термотропных жидкокристаллических структур полимерной матрицы и переходом системы в стационарное состояние с отрицательной обратной связью, обеспечивающей динамическую адаптацию трибосистемы к заданным условиям эксплуатации.
\end{abstract}

DOI: 10.21883/JTF.2017.02.44134.1955

\section{Введение}

Полимерные композиционные материалы на основе политетрафторэтилена (ПТФЭ) широко используются в металлополимерных узлах трения (трибосистемах) машин и технологического оборудования различных отраслей машиностроения благодаря хорошим антифрикционным свойствам при недостаточно высокой износостойкости. Поэтому создание новых антифрикционных полимерных композиционных материалов (ПКМ) на основе ПТФЭ, обладающих более высокой износостойкостью, адаптирующихся к внешнему энергетическому воздействию, является одной из важнейших задач современного трибоматериаловедения и триботехники [1,2]. Наиболее перспективным направлением разработки таких ПКМ можно считать метод структурной модификации полимерной матрицы структурно-активными наполнителями различной химической природы и формы микрои наноразмерных частиц (волокнистых, дисперсных порошков). Перспективность названного направления обусловлена также тем, что в условиях фрикционного взаимодействия развиваются физико-химические процессы многоуровневого структурного модифицирования и самоорганизации, которые играют определяющую роль в обеспечении высокой износостойкости полимерного композита и долговечности металлополимерного узла трения.

Основная закономерность, связывающая напряжение, абсолютную температуру и долговечность твердых тел различной природы, известная как уравнение С.Н. Журкова, формально характеризует роль теплового движения частиц в прочности материала и отражает кинетическую концепцию долговечности нагруженного тела [3]. Эта закономерность не содержит в явном виде фундаментальных теплофизических (термодинамических) параметров теплового движения: теплоемкости, теплового расширения, энтропии. Однако результаты работ, выполненных рядом исследователей на различных материалах, показывают, что в объеме образцов при различных видах нагружения, а также при фрикционном взаимодействии в поверхностном слое материалов происходят однотипные структурно-энергетические процессы, приводящие к накоплению микродефектов и разрушению образцов. Они имеют общую природу и зависимость от уровня внешнего энергетического воздействия, следовательно, могут быть описаны на основе всеобщих законов термодинамики с использованием термодинамических функций состояния.

Процессы формирования структуры композиционных материалов в условиях синтеза и их фрикционного взаимодействия можно также рассматривать с позиций эволюционных процессов в материальных системах. При таком подходе любая трибосистема, включая металлополимерную, развивается по общим закономерностям эволюции, когда проявляется способность системы к ее структурной самоорганизации и структурной приспосабливаемости $[4,5]$.

На основании изложенного металлополимерную трибосистему можно рассматривать как открытую термодинамическую систему и описывать ее, используя термодинамические функции и параметры (внутренняя энергия, энтропия, теплоемкость и др.). При установившемся режиме трения и изнашивания разрушение микрообъемов на поверхности трения сопровождается постоянным переходом все новых микрообъемов приповерхностных слоев в критическое состояние, при котором плотности внутренней энергии и энтропии достигают уровня, достаточного для разрушения межмолекулярных и молекулярных (химических) связей. Состояние трибосистемы при таком процессе характеризуется как стационарное термодинамическое состояние, при котором стационарный поток тепла из зоны трения обеспечивает постоянство градиента температур и производства энтропии во времени.

Согласно гипотезе И. Пригожина о локальном равновесии внутри глобально неравновесных систем при 
стационарном состоянии трибосистемы, скорость возникновения энтропии становится не только постоянной, но и минимальной для заданных параметров внешнего энергетического воздействия [6]. Это свойство стационарного состояния особенно важно для трибосистем, так как дает принципиальную возможность минимизировать скорость накопления энтропии и, следовательно, снижать скорость изнашивания при установившемся режиме трения.

\section{Методика исследования}

С целью изучения и реализации условий перехода металлополимерной трибосистемы в стационарное состояние с минимальной скоростью накопления энтропии и скоростью изнашивания исследовали металлополимерные пары трения с полимерными нанокомпозитами на основе ПТФЭ (фторопласт-4ПН по ГОСТ 10007-80), содержащими наномодификаторы различной химической природы и различной геометрической формы наночастиц. Первый наномодификатор - углеродные нанотрубки (УНТ) марки Craphistrength фирмы Arkemac, второй - двуокись кремния $\mathrm{SiO}_{2}$ в виде порошка марки БС-120 с размером частиц 19-27 nm. Оба композита также содержали по 8.0 mass.\% микроразмерного порошка скрытокристаллического графита (СКГ).

Исследование механических свойств названных нанокомпозитов проводили на разрывной машине „Zwick/Roell“" с автоматической системой измерения, обработки и оформления результатов измерений при погрешности измерений не более $5 \%$.

Исследование температурных зависимостей характеристик вязкоупругих свойств нанокомпозитов на основе ПТФЭ проводили на динамическом механическом анализаторе DMA модели 242DNETZCH.

Наиболее важное значение для нанокомпозитов триботехнического назначения имеет их износостойкость, оцениваемая по скорости изнашивания. Исследование концентрационных зависимостей скорости изнашивания композитов проводили на машине трения УМТ 2168 по схеме трения „палец-диск“ одновременно трех цилиндрических образцов при фрикционном взаимодействии со стальным контртелом без смазки в течение $3 \mathrm{~h}$.

\section{Результаты и их обсуждение}

Результаты исследования характеристик механических свойств нанокомпозитов показали, что композиты с порошкообразным наномодификатором БС-120 и композиты с волокнистым наномодификатором в виде УНТ имеют практически одинаковый предел прочности при растяжении. При этом модуль упругости композита с волокнистым модификатором (УНТ) на 50\% выше. Эти результаты свидетельствуют о том, что введение в матрицу модификаторов с частицами существенно

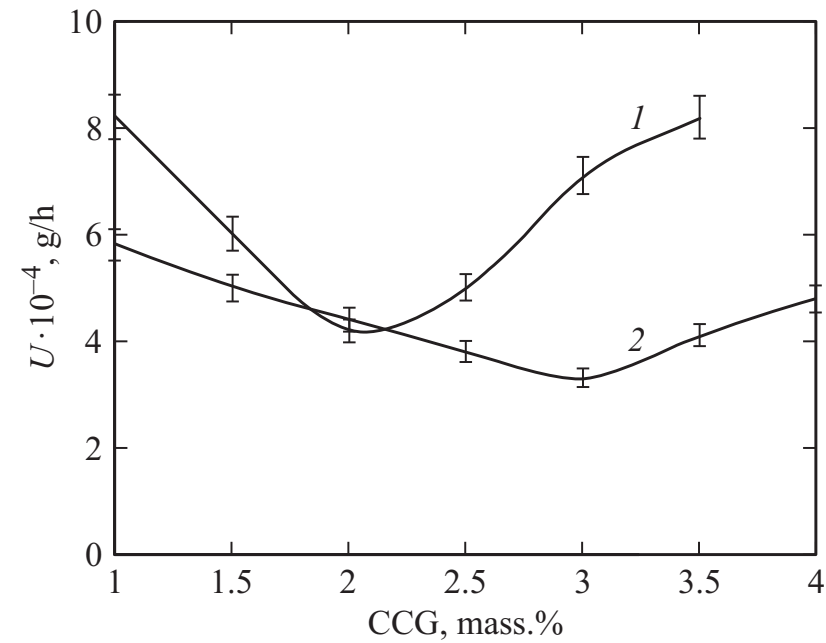

Рис. 1. Концентрационные зависимости скорости изнашивания нанокомпозитов: 1 - СКГ 8 mass. $\%+$ УНТ, $2-$ СКГ 8 mass. $\%+$ БC- 120 .

различной геометрической формы оказывает значительное влияние на процесс самоорганизации надмолекулярной аморфно-кристаллической структуры ПТФЭ и характеристики упругих свойств нанокомпозита. Полученные концентрационные зависимости (рис. 1) скорости изнашивания ПКМ с двумя названными наномодификаторами имеют экстремальный характер. При концентрации наномодификаторов 2.0 mass.\% скорости изнашивания нанокомпозитов практически одинаковы $(4.2-4.3) \cdot 10^{-4} \mathrm{~g} / \mathrm{h}$ в пределах доверительного интервала. Однако минимальная скорость изнашивания образцов ПКМ с волокнистым наномодификатором УНТ наблюдается при концентрации 2.0 mass.\%, а у образцов с порошкообразным наномодификатором БС-120 - при 3.0 mass.\% и равна $3.3 \cdot 10^{-4} \mathrm{~g} / \mathrm{h}$. Это на $30 \%$ меньше минимальной скорости изнашивания нанокомпозита с волокнистым модификатором УНТ и в 350 раз меньше скорости изнашивания чистого ПТФЭ при одинаковых условиях трения.

Экстремальный характер полученных зависимостей и значительное снижение скорости изнашивания, т. е. повышение износостойкости полимерных нанокомпозитов, также позволяют говорить о проявлении наноструктурной самоорганизации в полимерном нанокомпозите и переходе металлополимерной трибосистемы в стационарное состояние с минимальным значением и минимальной скоростью накопления энтропии. При этом процесс самоорганизации, согласно определению [6], обладает асимптотической устойчивостью, обусловленной возникновением отрицательной обратной связи, которая способствует восстановлению самоорганизующейся структуры наполненного полимера и предотвращению еe разрушения, придавая модифицированной структуре свойство динамической адаптации $[7,8]$ к заданным условиям эксплуатации.

Таким образом, металлополимерная трибосистема как открытая термодинамическая система в определенном 
Концентрация химических элементов в поверхностном слое и объеме образцов после испытания на машине трения

\begin{tabular}{|c|c|c|c|c|c|c|c|c|c|c|c|}
\hline \multirow{3}{*}{$\begin{array}{l}\text { Шифр } \\
\text { ПКМ }\end{array}$} & \multicolumn{11}{|c|}{ Концентрация химических элементов в ПКМ, mass.\% } \\
\hline & \multicolumn{5}{|c|}{ в объеме образца } & \multicolumn{6}{|c|}{ в приповерхностном слое } \\
\hline & $\mathrm{F}$ & $\mathrm{C}$ & $\mathrm{O}$ & $\mathrm{Si}$ & $\mathrm{Ca}$ & $\mathrm{F}$ & $\mathrm{C}$ & $\mathrm{O}$ & $\mathrm{Si}$ & $\mathrm{Fe}$ & $\mathrm{Cl}$ \\
\hline ПКМ-1 & 66.01 & 28.37 & 4.48 & 1.13 & - & 63.31 & 22.25 & 13.59 & 0.86 & - & - \\
\hline ПКМ-2 & 72.14 & 22.29 & 4.13 & 1.49 & - & 38.43 & 13.76 & 11.30 & 5.3 & 27.67 & 0.58 \\
\hline ПКМ-3 & 62.24 & 26.36 & 6.66 & 4.43 & 0.3 & 60.03 & 24.89 & 13.50 & 1.59 & - & - \\
\hline
\end{tabular}

диапазоне внешних энергетических возмущений может устойчиво работать в автоматическом режиме и с определенной степенью точности поддерживать постоянной минимальную силу трения, температуру в зоне трения и производство энтропии. Это становится возможным благодаря энергетическим сигналам обратной связи, формирующимся в трибосистеме вследствие физикохимических процессов в условиях фрикционного взаимодействия [9-11].

Подтверждением обоснованности этого вывода могут служить результаты исследования поверхностей трения рассматриваемых нанокомпозитов методом электронной микроскопии с анализом элементного состава ПКМ. Установлено, что после испытания на машине трения концентрация химических элементов в тонком поверхностном слое композита в зоне трения отличается от концентрации этих элементов в объеме образцов (таблица). Следовательно, в зоне контакта ПКМ с металлическим контртелом развиваются межфазные, химические и диффузионные процессы, которые влияют на структуру и химический состав композита (см. таблицу) в зоне фрикционного взаимодействия.

Как видно из таблицы, содержание всех элементов в поверхностном слое отличается от содержания их в объеме как в сторону увеличения $(\mathrm{O}, \mathrm{Si})$, так и в сторону уменьшения (F, C). Кроме того, после испытаний в одном образце присутствуют два новых элемента $\mathrm{Fe}$ и $\mathrm{Cl}$. Необходимо отметить наибольшее (в 3 раза) увеличение концентрации кислорода в приповерхностном слое, что свидетельствует о развитии интенсивных окислительных процессов при трении в воздушной среде.

Полученные результаты также свидетельствуют о том, что в условиях трения в полимерном нанокомпозите развиваются сложные физико-химические процессы, включающие процессы наноструктурной самоорганизации, которые в конечном итоге вызывают значительное изменение механических и триботехнических свойств полимерного нанокомпозита.

Результаты исследования методами динамического анализа характеристик вязкоупругости и релаксационных и фазовых переходов в полимерных нанокомпозитах в условиях динамического нагружения показали, что процесс граничного трения сопровождается непрерывной механической „накачкой“ возбужденных состояний в трибосистеме. Поэтому для достижения стационарного состояния с минимальным производством энтропии необходим периодический сброс избыточной энергии с верхних уровней системы на нижележащие. При этом в трибосистеме должны реализоваться различные механизмы диссипации избыточной энергии, например за счет теплопроводимости, накопления и выхода структурных дефектов в контактирующих металлических и полимерных твердых телах.

Следовательно, в металлополимерной трибосистеме, устойчиво работающей в режиме граничного трения, должен реализовываться набор стационарных структурно-фазовых состояний, экспериментальная регистрация которых может быть выполнена путем регистрации отклика трибосистемы на изменение внешних энергетических воздействий. В работах автора $[9,10]$ показано, что при трении композиционных материалов на основе ПТФЭ при увеличении температуры выше температуры плавления кристаллитов формируется аморфная фаза, в которой сохраняется послойное расположение макромолекул ПТФЭ, что свидетельствует о самоорганизации новой упорядоченной структуры, характерной для жидкокристаллических структур. Исследования термодинамических характеристик фазовых переходов в области температуры плавления кристаллической фазы ПТФЭ методом дифференциально-термического анализа показали, что термограммы чистого ПТФЭ и композиционных материалов на его основе содержат пики трех эндотермических переходов.

Низкотемпературный пик при $T_{1}=603 \mathrm{~K}$ соответствует фазовому переходу первого рода - плавлению кристаллитов ПТФЭ и формированию структуры термотропных жидких кристаллов. Второй эндотермический пик при $T_{2}=637 \mathrm{~K}$ соответствует переходу к другому типу жидкокристаллической структуры (ЖКС). Третий высокотемпературный пик при $T_{3}=680 \mathrm{~K}$ соответствует переходу ПТФЭ в полностью аморфное неупорядоченное состояние. Температурный интервал $\Delta T=T_{3}-T_{1}$ определяет температурную область существования ЖКС, являющихся результатом процесса наноструктурной самоорганизации нанокомпозитов на основе ПТФЭ. Таким образом, анализ результатов рентгеноструктурного и термографического исследований показывает, что повышение температуры в зоне фрикционного взаимодействия создает условия для развития процесса самоорганизации, включающего фазовые переходы: кристаллической фазы в аморфную, аморфной в жидкокристаллическую с послойной термотропной ЖКС, обеспечивающей легкое скольжение слоев ПТФЭ [10,11]. 


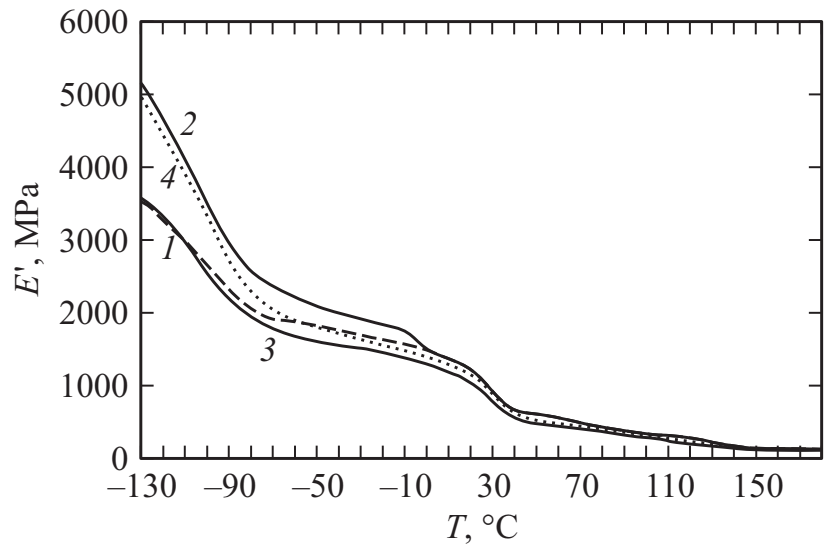

Рис. 2. Температурные зависимости динамического модуля упругости ПКМ: 1 - ПТФЭ, $2-$ ПТФЭ + СКГ, $3-$ ПТФЭ + СКГ + 1.0\% БС-120, $4-$ ПТФЭ + СКГ $+2.0 \%$ БС-120.

Повышение температуры в зоне фрикционного контакта оказывает существенное влияние на вязкоупругие свойства полимерных композитов на основе ПТФЭ $[9,11]$ вследствие развивающихся процессов самоорганизации. Поэтому представляло научный и практический интерес исследование влияния концентрации наполнителей модификаторов на температуру релаксационных переходов и динамический модуль упругости композитов. С этой целью исследовали температурные зависимости динамического модуля упругости и тангенса угла механических потерь на образцах нанокомпозитов с различной концентрацией БС-120 при постоянной концентрации СКГ (8.0 mass.\%). Результаты исследований показали, что изменение температуры в широком интервале отрицательных и положительных температур оказывает значительное влияние на температуру релаксационных переходов и величину динамического модуля упругости ПТФЭ и полимерных композитов на его основе. Установлено, что многокомпонентные системы исследуемых композиционных материалов, в составе которых 8.0 mass.\% - СКГ и 1.0-2.0 mass.\% наномодификатора БС-120, имеют более высокий динамический модуль упругости по сравнению с модулем упругости чистого ПТФЭ (рис. 2).

При этом при повышении температуры от $-130^{\circ} \mathrm{C}$ до $+180^{\circ} \mathrm{C}$ динамический модуль упругости чистого ПТФЭ и ПТФЭ-композитов снижается в 20 и 50 раз соответственно, что связано с влиянием модификаторов и температуры на структурно-фазовое состояние полимерной матрицы. При температурах ниже температуры стеклования $\left(-92^{\circ} \mathrm{C}\right)$ подвижность полимерных цепей утрачивается вследствие значительного повышения энергетических барьеров (энергии активации движения), особенно в присутствии наполнителя, и ПКМ переходит в стеклообразное состояние. С повышением температуры наблюдается повышение интенсивности сегментального движения структурных элементов ПТФЭ (звеньев, атомных групп и сегментов) и ПКМ пере- ходит в высокоэластическое состояние. Это состояние представляет большой интерес, так как оно характерно для условий эксплуатации металлополимерных трибосистем, что следует учитывать при разработке полимерных нанокомпозитов для эксплуатации в широком интервале положительных и отрицательных температур.

\section{Заключение}

1. В условиях фрикционного взаимодействия в полимерных нанокомпозитах развиваются физико-химические процессы изменения химического и фазового составов, а также морфологии надмолекулярной структуры поверхностного слоя, которые вызывают изменение характеристик механических и триботехнических свойств ПКМ.

2. Введение в ПТФЭ модификаторов различной химической природы и концентрации и изменение температуры оказывают различное влияние на динамический модуль упругости и температуру релаксационных переходов. С повышением температуры (от $-130^{\circ} \mathrm{C}$ до +180$)$ динамический модуль упругости снижается в десятки раз с различной интенсивностью в различных интервалах температуры, при этом модуль упругости чистого ПТФЭ значительно меньше модуля полимерных нанокомпозитов.

3. Установлено, что в условиях трения и изнашивания в металлополимерных трибосистемах развиваются процессы наноструктурной самоорганизации, характеризующиеся релаксационными и фазовыми переходами в полимерных композиционных материалах с образованием термотропных жидкокристаллических структур полимерной матрицы, например ПТФЭ, и переходом системы в стационарное состояние с отрицательной обратной связью, обеспечивающей динамическую адаптацию трибосистемы к заданным эксплуатационным условиям.

Работа выполнена при финансовой поддержке РФФИ в рамках научного проекта 16-58-00037-,Бел-а“.

Автор благодарит О.В. Кропотина, О.В. Малий, О.В. Чемисенко за участие в проведении исследований, анализе и оформлении результатов работы.

\section{Список литературы}

[1] Свириденок А.И., Мышкин Н.К., Ковалева А.Н. // Трение и износ. 2015. Т. 36. Вып. 6. С. 591-595.

[2] Mashkov Yu.K., Kropotin O.V., Chemisenko O.V, Shil'ko S.V. I/ J. Frict. Wear. 2015. Vol. 36. N 6. P. 476-480.

[3] Машков Ю.К., Кропотин О.В. // Изв. Самарского науч. центра РАН. 2011. Т. 13. Вып. 4. С. 811-817.

[4] Костецкий Б.И. // Трение и износ. 1985. Т. 6. Вып. 2. C. $201-212$.

[5] Машков Ю.К. // В сб.: Долговечность трущихся деталей машин. М.: Машиностроение, 1990. Вып. 4. С. 219-244.

[6] Николис Г., Пригожсин И. Самоорганизация в неравновесных системах. М.: Мир, 1979. 512 с. 
[7] Поляков С.А., Куксенова Л.И. // Изв. Самарского науч. центра РАН. 2011. Т. 13. Вып. 4. С. 853-856.

[8] Гаркунов Д.Н., Машков Ю.К., Маринич Т.Л. // В сб.: Долговечность трущихся деталей машин / Под ред. Д.Н. Гаркунова. М.: Машиностроение, 1987. Вып. 2. С. 85-92.

[9] Машков Ю.К., Овчар 3.Н., Суриков В.И., Калистратова Л.Ф. Композиционные материалы на основе политетрафторэтилена. Структурная модификация. М.: Машиностроение, 2005. 240 с.

[10] Машков Ю.К. // Трение и износ. 2002. Т. 23. Вып. 6. C. $661-665$.

[11] Mashkov Yu.K. // J. Frict. Wear. 2012. Vol. 33. N 5. P. 354-358. 